\title{
Fertile diploid males in the ant Cataglyphis cursor: a potential cost of thelytoky?
}

\author{
Claudie Doums • Camille Ruel • Johanna Clémencet • \\ Pierre Fédérici • Laurent Cournault • Serge Aron
}

\begin{abstract}
Under the hymenopteran single-locus complementary sex-determination system, production of diploid males results from homozygosity at the sex-determiner locus. This arises when both parents transmit identical alleles at the locus to the offspring. In species reproducing asexually through thelytokous parthenogenesis, production of diploid males may also occur when the sex locus undergoes recombination and becomes homozygous in the offspring. Diploid males represent a substantial genetic load in hymenopteran populations because they often produce unviable sperm or sire sterile triploid female offspring. In the Mediterranean ant Cataglyphis
\end{abstract}

Electronic supplementary material The online version of this article (doi:10.1007/s00265-013-1606-6) contains supplementary material, which is available to authorized users.

C. Doums $\cdot$ P. Fédérici $\cdot$ L. Cournault

Laboratoire Ecologie et Evolution, CNRS, UPMC-Paris 6,

UMR 7625, 75252 Paris Cedex 05, France

C. Doums

Ecole Pratique des Hautes Etudes, 46 rue de Lille, 75013 Paris, France

C. Ruel

Estación Biológica de Doñana, Doñana CSIC; Avenida Americo

Vespucio s/n, 41013 Sevilla, Spain

J. Clémencet

UMR Peuplements Végétaux et Bio-Agresseurs en Milieu Tropical, Université de La Réunion, 15 avenue René Cassin, 97715 Saint-Denis, La Réunion, France

S. Aron

Evolutionary Biology and Ecology, Université Libre de Bruxelles,

50 avenue F. D. Roosevelt, 1050 Brussels, Belgium

C. Doums $(\triangle)$

Laboratoire Ecologie et Evolution, UMR 7625 CNRS, UPMC, Bat A, 7ème étage, CC 237, 7 quai Saint-Bernard,

75252 Paris Cedex 05, France

e-mail: cdoums@snv.jussieu.fr cursor, the queen and workers can produce female offspring through automictic thelytokous parthenogenesis with central fusion, a mode of parthenogenesis that increases homozygosity. We report, for the first time, the presence of about $39 \%$ of colonies producing adult diploid males (seven colonies out of 18). Overall, $8 \%$ of adult males were diploid (12 diploid males out of the 146 males genotyped). Genotyping workers from the seven colonies producing diploid males showed that three diploid males were sons of queens and produced by thelytoky, six were probably sons of workers also produced by thelytoky and three were non-natal. Furthermore, the mating of a diploid male with two virgin queens in the laboratory led to the production of sterile triploid workers, which shows that diploid males in C. cursor are fertile, mate successfully and produce viable and functional but probably sterile female offspring. Because diploid males originate from thelytokous reproduction, they are only produced during sexual production and hence do not impair colony growth, which could explain why they are not removed at early brood stages.

Keywords Diploidmales · Triploid females · Parthenogenesis · Worker reproduction $\cdot$ Microsatellites $\cdot$ Social insects

\section{Introduction}

The negative effect of inbreeding on individual fitness (i.e., inbreeding depression) is considered a key parameter affecting the evolution of reproductive systems (Engelstadter 2008; Charlesworth and Willis 2009). In several Hymenoptera, sex is determined by the complementary sex-determination mechanism (CSD): males are usually haploid and, therefore, hemizygous at the sex-determining locus or loci, whereas females are diploid and heterozygous. However, inbreeding can lead to the production of diploid individuals homozygous at the sex locus or loci that develop into diploid males (Cook and Crozier 1995; van Wilgenburg et al. 2006; Heimpel and de Boer 2008; 
Asplen et al. 2009; Schmeider et al. 2012). Production of diploid males is generally considered to be a genetic load in hymenopteran populations. They often produce unviable sperm and, when they are fertile, they impose a cost to their female partner who produces triploid offspring that may be less viable or sterile (Darvill et al. 2012; Harpur et al. 2013). In social Hymenoptera (ants, bees and wasps), diploid male production (DMP) has an additional cost because it highly impairs colony growth since larvae that should develop into workers become males that do not contribute to colony productivity (Ross and Fletcher 1986; Whitehorn et al. 2009). Resources invested into diploid males are therefore wasted and theoretical studies show that DMP can increase the risk of population extinction (Zayed and Packer 2005). In honey bees, workers remove diploid male brood (Woyke 1963; Santomauro et al. 2004), but adult diploid males are known to occur in many other social hymenopteran species (reviewed in Darvill et al. 2012). In ants, for example, diploid males have been observed in more than 20 species belonging to different subfamilies (Table 1 in Cournault and Aron 2009; Darvill et al. 2012). However, triploid females have been reported only rarely (in endangered populations of Bombus florigelus, Takahashi et al. 2008; in Polistes dominulus, Liebert et al. 2005; in introduced populations of Solenopsis invicta, Krieger et al. 1999 and in Tapinoma erraticum, Cournault and Aron 2009). This suggests that diploid males have a low success in fertilizing females or that triploid females are less viable in natural populations. The cost of diploid males is likely to be an important component underlying the evolution of reproductive and breeding systems in social Hymenoptera. For instance, the risk of DMP could favour the evolution of multiple mating by females (polyandry) (Pamilo et al. 1994; Crozier and Fjerdingstad 2001).

Recently, an increasing number of species have been found to reproduce by thelytokous parthenogenesis (Wenseleers and Van Oystaeyen 2011; Rabeling and Kronauer 2013). In the few social insect species where it has been studied, parthenogenesis is automictic with central fusion (honey bees: Apis mellifera capensis, Verma and Ruttner 1983; ants: Cataglyphis cursor, Pearcy et al. 2006; Wasmania auropunctata, Rey et al. 2011; Platythyrea punctata, Kellner and Heinze 2011). This mode of parthenogenesis results from the fusion of two of the products of meiosis that were separated during the first meiotic cellular division (Suomalainen et al. 1987). The offspring genotypes are thus similar to their mother except for loci that undergo recombination and become homozygous. The probability of undergoing recombination increases as the distance between the locus and the centromere increases, and varies from zero to $33 \%$ (Pearcy et al. 2006, 2011). Diploid males might therefore be produced after recombination at the sex-determining locus or loci (Pearcy et al. 2009). Inbreeding and the production of diploid males can impair the evolution of thelytokous parthenogenesis in social Hymenoptera (van Wilgenburg et al. 2006; Goudie et al. 2012). In the thelytokous Cape honey bee $A$. mellifera capensis, low recombination rates around the identified sex-determining locus were thought to reduce DMP (Baudry et al. 2004). However, Goudie et al. (2012) recently showed that recombination does occur at the sex locus and produces diploid males, but these are only observed in eggs and first instar larvae as they are eaten by workers at early larval stages (Woyke 1963).

In this study, we report for the first time the occurrence of diploid males in natural populations of the ant $C$. cursor, a species where both the queen and the workers have the ability to reproduce by thelytokous parthenogenesis (Cagniant 1979; Pearcy et al. 2004). No such diploid males have been reported in this species in the only natural population studied so far (Pearcy et al. 2009). Yet, we incidentally detected fertile diploid males while doing experimental mating in the laboratory. This prompted us to genotype 146 males produced by 18 colonies from two additional populations other than the one studied by Pearcy et al. (2009) and workers from the same colonies, in order to determine (1) the proportion of diploid males in the two populations, (2) whether these males were produced by the queen or workers and (3) if diploid males were produced by the queen, whether they arose from mating with a related male or from thelytokous parthenogenesis. In $C$. cursor, males can mate with several females (Cronin et al. 2011); we report on two incidental matings of a single diploid male with two queens in the laboratory.

\section{Material and Methods}

\section{Genetic analyses}

Males originated from 18 colonies collected in Southern France. Four colonies were excavated in Argelès at the beginning of June 2006, seven were collected in the same locality at the end of May 2007 and seven were excavated from Saint Cyprien (9.5 km from Argelès) at the end of May 2007 (Table 1, see also Doums et al. 2013 for details on colonies collected in 2007). All colonies showed sexual activity at the nest entrance, where non-natal males were seeking mates (Lenoir et al. 1988; Cronin et al. 2011) and indeed all contained gynes (young queens). A total of 146 males were collected either within the nest during excavation (123) or at the nest entrance while mating was taking place (23).

We genotyped all the males, queens and gynes excavated. Individuals from the 14 colonies collected in May 2007 were genotyped at 12 microsatellites (multiplex 1 and 2: cc11, cc26, cc46, cc63, cc76, cc89; multiplex 3 and 4: cc51, cc58, cc61, cc65, cc99, cc100; Doums et al. 2013). Queen and gyne genotypes as well as the mode of gyne production (by thelytoky or sexual reproduction) were retrieved from Doums et al. (2013) (the data file can be found in dryad 
database ref: dryad10.5061/dryad.5488t). Males were specifically genotyped for this study. Individuals from the four colonies collected in June 2006 were genotyped at six microsatellites (multiplex 1 and 2) (Clémencet et al. 2005). The mode of queen production in these four colonies was determined following Doums et al. (2013); the presence of the queen was determined after ovary dissection and observation of yellow bodies, as many gynes had already lost their wings but did not start egg-laying. In one of the four colonies, the mother queen was not found and her genotype was inferred from her parthenogenetically produced gynes. All males identified as diploids were extracted and genotyped twice in order to confirm their ploidy level. An additional sample of 265 workers from the seven colonies that produced diploid males was genotyped at six microsatellite loci (multiplex 1 and 2). The genotype of workers was already published for one of these colonies, col54 (dryad 10.5061/dryad.5488t; Doums et al. 2013).

DNA was extracted from the thorax of males using Qiagen DNA tissue kit QIAquick 96 and eluted in $150 \mu$ l elution buffer. PCR conditions were identical to those described in
Doums et al. (2013). Amplification products were loaded together on an ABI Prism 310 sequencer (Applied Biosystems) and allele sizes were estimated using Genescan software. A previous study detected no linkage disequilibrium or departure from Hardy-Weinberg equilibrium in the two populations studied (Doums et al. 2013). Relatedness was estimated using the software Relatedness 5.0.8 (Queller and Goodnight 1989) by weighting colonies equally and with standard error obtained by jackknifing over colonies. We used the allelic frequencies obtained over a large sampling of 42 colonies (22 from Argelès and 20 from Saint Cyprien, see details in Doums et al. 2013) and defined each population as a different deme. We hence assumed that allelic frequencies did not change between 2006 and 2007. Note that the estimates of relatedness did not qualitatively differ when allelic frequencies were not included in the file and were estimated from the few colonies studied here.

Genotypes of workers were used to assess the origin of diploid males, as males could be produced by queen thelytoky, queen mating with a related male or by thelytokous worker reproduction (Table 2). Patrilines were determined manually

Table 1 Number of diploid and haploid males found in each colony and their potential origin

\begin{tabular}{|c|c|c|c|c|c|c|c|c|}
\hline \multirow[t]{2}{*}{ Colony } & \multirow[t]{2}{*}{ Pop } & \multirow[t]{2}{*}{ Gynes } & \multirow[t]{2}{*}{ Males } & \multicolumn{3}{|c|}{ Diploid males } & \multicolumn{2}{|c|}{ Haploid males } \\
\hline & & & & Queen & $\mathrm{NN}$ & W & Queen & $\mathrm{W}$ or $\mathrm{NN}$ \\
\hline 1081 & Argelès 2006 & 3PP & 20 & 0 & 0 & 0 & 20 & 0 \\
\hline 1090 & Argelès 2006 & $6 \mathrm{PP}$ & 11 & 0 & 0 & $2+1^{a}$ & 5 & 3 \\
\hline 1092 & Argelès 2006 & 20PP & 10 & 0 & 0 & 0 & 0 & $10^{\mathrm{b}}$ \\
\hline 1095 & Argelès 2006 & $53 \mathrm{SP}$ & 15 & 0 & 0 & 2 & 10 & 3 \\
\hline 52 & Argelès 2007 & $1 \mathrm{PP}^{\mathrm{c}}$ & 2 & 0 & 0 & 0 & 0 & 2 \\
\hline 54 & Argelès 2007 & $33 \mathrm{SP}^{\mathrm{c}}$ & 6 & 0 & 1 & 1 & 0 & 4 \\
\hline 55 & Argelès 2007 & $14 \mathrm{PP}^{\mathrm{c}}$ & 2 & 1 & 0 & 0 & 1 & 0 \\
\hline 58 & Argelès 2007 & $10 \mathrm{PP}^{\mathrm{c}}$ & 10 & 0 & 0 & 0 & 0 & 10 \\
\hline 60 & Argelès 2007 & $1 \mathrm{PP}^{\mathrm{c}}$ & 3 & 0 & 0 & 0 & 2 & $1^{\mathrm{b}}$ \\
\hline 73 & Argelès 2007 & $2 \mathrm{PP}+6 \mathrm{SP}^{\mathrm{c}}$ & 3 & 0 & 0 & 0 & 3 & 0 \\
\hline 75 & Argelès 2007 & $3 \mathrm{PP}+9 \mathrm{SP}^{\mathrm{c}}$ & 12 & 0 & 0 & 0 & 1 & 11 \\
\hline 100 & St Cyprien 2007 & $11 \mathrm{PP}^{\mathrm{c}}$ & 8 & 1 & 1 & 0 & 5 & 1 \\
\hline 104 & St Cyprien 2007 & $4 \mathrm{SP}^{\mathrm{c}}$ & 5 & 0 & 0 & 0 & 5 & 0 \\
\hline 105 & St Cyprien 2007 & $19 \mathrm{PP}^{\mathrm{c}}$ & 8 & 1 & 0 & 0 & 5 & 2 \\
\hline 106 & St Cyprien 2007 & $16 \mathrm{SP}^{\mathrm{c}}$ & 3 & 0 & 0 & 0 & 3 & 0 \\
\hline 110 & St Cyprien 2007 & $16 \mathrm{SP}^{\mathrm{c}}$ & 10 & 0 & 0 & 0 & 10 & 0 \\
\hline 120 & St Cyprien 2007 & $11 \mathrm{PP}+1 \mathrm{SP}^{\mathrm{c}}$ & 7 & 0 & $1^{\mathrm{b}}$ & 0 & 0 & $6^{\mathrm{b}}$ \\
\hline 123 & St Cyprien 2007 & $21 \mathrm{PP}+28 \mathrm{SP}^{\mathrm{c}}$ & 11 & 0 & 0 & 0 & 6 & $5^{\mathrm{b}}$ \\
\hline
\end{tabular}

Males harbouring only maternal alleles were considered as queen-produced; males harbouring some non-maternal alleles were considered as worker produced (W) or non-natal (NN). Heterozygous diploid males with no common alleles with the queen could not have been produced by the queen and were considered non-natal (NN; see Table 2). We also provide for each colony the number of parthenogenetically produced (PP) and sexually produced gynes (SP). For colonies collected in 2007, the data were obtained from Doums et al. (2013)

${ }^{\text {a }}$ The origin of the diploid male is ambiguous

${ }^{\mathrm{b}}$ Males collected outside the nest

${ }^{\mathrm{c}}$ Data obtained from Doums et al. (2013) 
and the number of effective patrilines ( $k e 3)$ estimated following Nielsen et al. (2003). We determined the origin of diploid or haploid males as indicated in Table 2. Note that a diploid male who belonged to a worker patriline could result from either thelytokous reproduction of a worker or from sexual reproduction of the queen if she had mated with a male sharing the same allele at the sex-determining locus. The former was unambiguous if at least one locus had undergone a recombination event. The latter would most likely occur when the queen mated with a related male, which would lead to an increased genetic relatedness between the queens and their partners. If no locus had undergone a recombination event, we estimated the probability of not observing a single recombination event if the diploid male was worker produced through thelytokous parthenogenesis $\left(P_{w}\right)$, as:

$P_{w}=\prod_{i}\left(1-R t_{i}\right)$

where $R t_{i}$ is the rate of transition from the heterozygous to homozygous state (obtained from Table 1 in Doums et al. 2013) for the heterozygote locus $i$ in the parental worker patriline. When the estimated Rt exceeded 0.33 , the theoretical maximal value expected under meiotic thelytoky with central fusion (Pearcy et al. 2006), we used the value 0.33 instead of the estimate.
Mating in the laboratory

Preliminary mating experiments were conducted using one male (from col42) and two virgin queens (from col24 and col26) born in the laboratory in May 2007. The male mated successively with the two virgin queens. The male died soon after mating and was lost. Because C. cursor males and queens mate multiply, we wanted to test whether a single mating was sufficient for the queens to lay eggs. To do so, each of the two queens was reared with a few hundred workers under standard conditions $\left(26^{\circ} \mathrm{C}, 12: 12\right.$ light/dark cycle $)$ in a plaster nest and was provided with mealworm, crickets, sugar and water ad libitum. They were then placed in an incubator kept at $12{ }^{\circ} \mathrm{C}$ for 2 months of hibernation. When removed from hibernation, the queens started producing eggs. In both colonies, all workers were marked using Unipaint marker px20 before the emergence of new workers. During the following 6 months, colonies 24 and 26 produced 219 and 76 workers, respectively. The two queens and a sample of unmarked workers (10 for colony 24,76 for colony 26 ) were killed at $-80^{\circ} \mathrm{C}$.

The genotypes of ten workers from both colonies were analysed using the 12 microsatellite markers described above. Once we realised that workers were triploid (see "Results"), we conducted a flow cytometric analysis on nine additional workers from col26 and ten from col24 that had been kept at $-80{ }^{\circ} \mathrm{C}$ to independently assess their ploidy level. This technique allows characterizing the nuclear DNA content by measuring the fluorescence reflection of stained DNA and has already been used in

Table 2 Origin of haploid and diploid males (queen-produced, worker produced or non-natal)

\begin{tabular}{|c|c|c|c|}
\hline & $\begin{array}{l}\text { Arrhenotoky } \\
\text { Haploid male }\end{array}$ & $\begin{array}{l}\text { Thelytoky } \\
\text { Diploid male }\end{array}$ & $\begin{array}{l}\text { Sexual reproduction } \\
\text { Diploid male }\end{array}$ \\
\hline Queen-produced & $\begin{array}{l}76 \\
\left(100 \% \text { alleles inherited from the queen }{ }^{a}\right)\end{array}$ & $\begin{array}{l}3 \\
\left(100 \% \text { alleles inherited from the queen }{ }^{a}\right)\end{array}$ & $\begin{array}{l}\text { 0 } \\
\text { (50\% alleles inherited from the } \\
\quad \text { queen's mate) } \\
\text { (No recombinant locus) }\end{array}$ \\
\hline Worker produced & $\begin{array}{l}\text { 0 } \\
\text { (50\% alleles inherited from the queen's mate) }\end{array}$ & $\begin{array}{l}\mathbf{5}+\mathbf{1} \text { ambiguous } \\
(50 \% \text { alleles inherited from the queen's mate) } \\
\text { (At least one recombinant locus }{ }^{\mathrm{b}} \text { ) }\end{array}$ & \\
\hline Non-natal & $\begin{array}{l}58 \text { including } 22 \text { sampled outside the nest } \\
\text { (No alleles inherited from the queen or queen's } \\
\text { mate for at least one locus) }\end{array}$ & $\begin{array}{l}3 \\
\text { (No alleles inherited from the queen for at least }\end{array}$ & one heterozygote locus) \\
\hline
\end{tabular}

The number of males observed for each origin is given in bold. The criteria used for identifying the origin of males are given between parentheses. Note that for haploid males, we could not ascertain that a given male was non-natal except when it was sampled outside the nest. However, in colonies for which workers were sampled, the presence of alleles not found in the queen and in workers indicated a non-natal origin of haploid males

${ }^{a}$ The probability that a worker-produced male only inherits maternal or paternal alleles by chance was low ( 0.016 with six loci and 0.0002 with 12 loci) when assuming equal transmission of maternal and paternal alleles

${ }^{\mathrm{b}}$ The probability of not observing at least one recombinant locus over 12 loci for a given individual was always higher than $5 \%$ because recombination can only be observed for heterozygous loci in the mother. However, over few males, not observing a single recombination event could strongly suggest that they originated from a queen matched-mating 
several ant species (Aron et al. 2003; Cournault and Aron 2008; Cournault and Aron 2009). Heads of workers were cut and individually crushed in DAPI solution (CyStain ${ }^{\circledR}$ DNA-1 step, PARTEC(C) and then analysed using a PA-I flow cytometer (PARTECC), Partec68 Gmbh, Münster, Germany).

\section{Results}

Diploid males

Of the 146 males analysed, $12(8.2 \%)$ were heterozygous at two to eight loci indicating that they were diploid. Diploid males were found in seven colonies out of 18 (i.e., $39 \%$ ), four from one population and three from the other population (Table 1). Three diploid males harboured maternal alleles only and were therefore produced by the queen (Table 2). Each of these males had at least one recombinant locus, which clearly demonstrates that they result from thelytokous reproduction by the queen and not sexual reproduction with a related male (Table 3). Three diploid males were non-natal, each hosting a minimum of four alleles that were not present in the colony queen (Table 3). One of these males was collected outside the nest, suggesting he had succeeded at dispersing and was attempting to mate with gynes at the nest entrance. The other two males were collected inside colonies that also contained non-natal haploid males (Table 1) but could not be the brother of any of the non-natal haploid males (they did not share common alleles with haploid males at their heterozygote loci). The genotype of one diploid male was ambiguous: he could be either the son of a worker from an undetected patriline or non-natal. Among the five remaining diploid males, one was homozygous for alleles identified in a worker patriline, showing that he was worker produced (Table 3). The other four diploid males had genotypes consistent with their production by a queen mated with a male harbouring an identical allele at the sex-determination locus, or by a worker reproducing by thelytokous parthenogenesis with no recombination event. Using the recombination rates of the loci given in Doums et al. (2013), we estimated the probability of not observing a recombination event to be higher than $5 \%$ for each diploid male (Table 3). Over the four males, the probability of not observing such an event was also higher than $5 \%(P=0.07)$. Even though one may not completely exclude the possibility that the four males were produced by the queen, these results suggest that the diploid males arose from worker reproduction but without observed recombination.

Genetic structure of diploid male-producing colonies

We investigated the genetic structure of the seven colonies that produced diploid males (see below; Table 4). One worker could not be the offspring of the queen as it shared no allele with the queen at one heterozygous locus (120W493 in col 120) and was thus removed from subsequent analysis. Forty-four patrilines were detected. Four contained a single worker that differed by only one locus from the genetically closest patrilines. For one of these patrilines, the allele at the discriminant locus differed by only a few base pairs and was interpreted as a mutation event or a PCR error. For the other three patrilines (one in P5 col 1095; two in P2 col 55), the discriminant locus was homozygous for an allele heterozygous in the closest patriline, and could therefore be explained by a parthenogenetic reproduction of a worker of the closest patriline. These discriminant loci were removed, and the four individuals assigned to their closest patrilines for the subsequent analysis. Seven other patrilines also contained a single worker, but they differed from other patrilines by more than three loci and were therefore considered as true patrilines. We found one instance $(0.33 \%)$ of asexual production of a worker by the queen in col 120 .

On average the number of patrilines per colony was 6.3, ranging from three to 12 as is usually observed in C. cursor (Fig. 1) (Pearcy et al. 2004; Fournier et al. 2008; Chéron et al. 2011b; Doums et al. 2013). The effective paternity was lower than the actual number of matings in five colonies and, accordingly, paternity was significantly skewed in four of these five colonies (Table 4). The average worker-worker relatedness of $0.50 \pm 0.03$ (see Table 4 for relatedness value per colony) was slightly higher than previously reported ( 0.36 in Pearcy et al. (2004); 0.44 in Chéron et al. (2011b); 0.42 in Doums et al. (2013)). The average relatedness between queens and their mates was close to zero confirming the absence of inbred mating $(R=-0.006 ; t$ test $=0.12 ; \mathrm{ddl}=6 ; P=0.91)$. These seven colonies therefore presented a sociogenetic structure typical for $C$. cursor (Pearcy et al. 2004; Chéron et al. 2011b; Doums et al. 2013).

The colonies producing diploid males were also similar to the other colonies with regard to the mode of queen reproduction, and produced gynes either by thelytokous parthenogenesis or by sexual reproduction (Table 1). In fact, genotypes indicative of gynes being produced by sexual reproduction could be either directly produced by the mother queen or indirectly produced through the thelytokous reproduction of sexually produced workers. Worker production of gynes can be detected only if thelytoky is associated with at least one recombination event (Doums et al. 2013). No such evidence of recombination was found in colony 1095 whose gynes were specifically analysed for this study. This is consistent with the conclusion of Doums et al. (2013) that gynes harbouring alleles from the colony queen and her mates are mostly, if not always, directly produced by the queen.

Haploid males

All haploid males collected outside the nest (22) were nonnatal, differing from the mother queen by at least seven alleles (median $=0.74 \%$, range $=42 \%, 83 \%$ ). Out of the other 112 


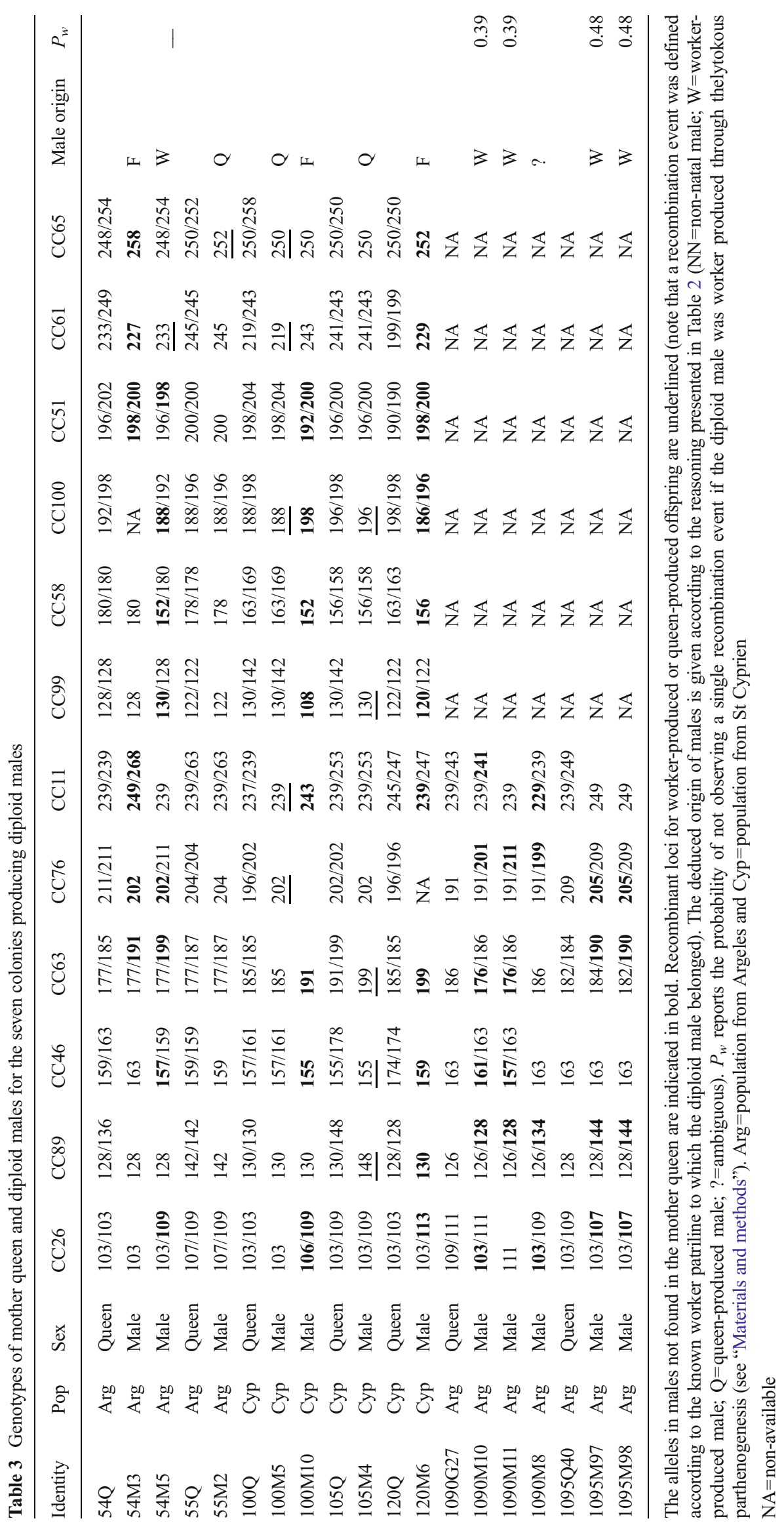


Fig. 1 Distribution of worker patrilines in the seven colonies producing diploid males. The different patrilines are represented by alternating grey and white boxes, and percentages correspond to the number of workers each contained. One or two white crosses in a box indicates that one or two diploid males were produced by the patriline

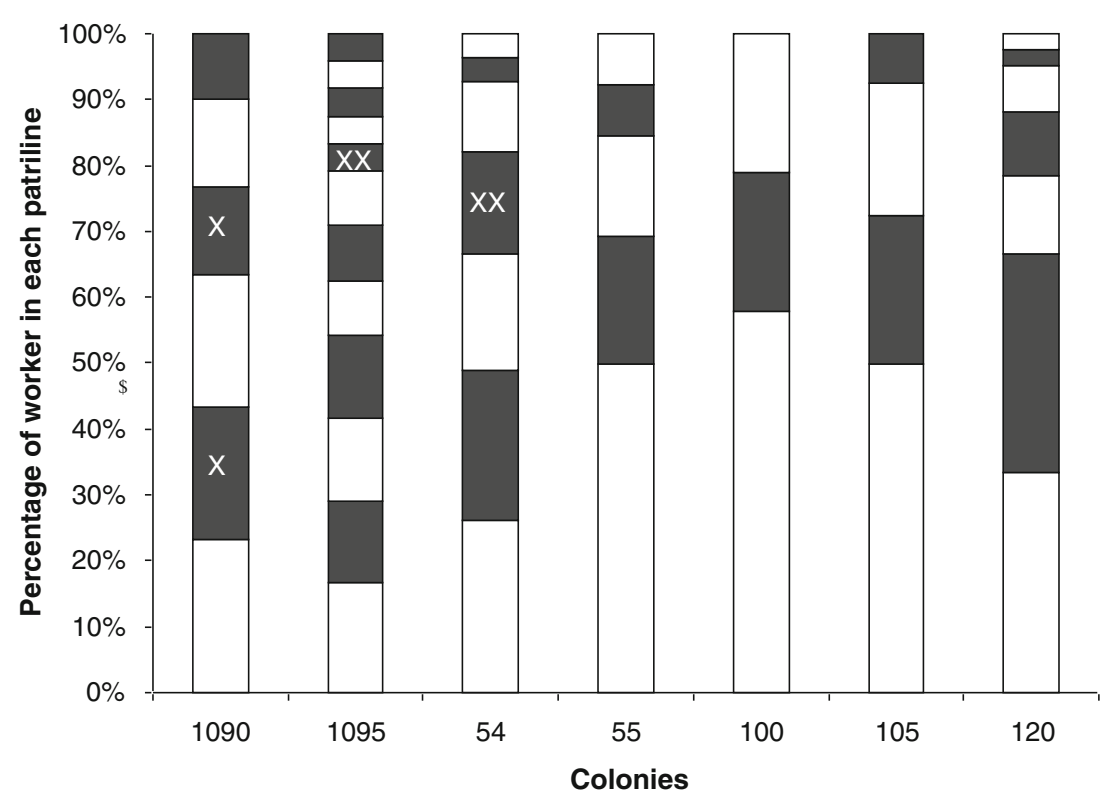

haploid males, 76 shared all their alleles with the queen and were therefore the queen's sons (Tables 1 and 2). The remaining 36 males differed from the queen by at least half of her alleles (median $=0.73 \%$, range $=42-100 \%$ ), the percentage of non-maternal alleles did not significantly differ from the one observed for the males collected outside (Wilcoxon test, $\mathrm{W}=397.5, P=0.99$ ). Moreover, in colonies where workers were genotyped, haploid males harboured genotypes that were not compatible with any of the worker patrilines identified within a colony. These results suggest that haploid males with non-maternal alleles were all non-natal and that workers produced no haploid males, as already reported by Pearcy et al. (2009).

\section{Experimental mating}

We genotyped 19 workers that were produced by two queens mated once, each with the same diploid male under laboratory conditions. All workers harboured three alleles at three to seven loci and were therefore triploids (supplementary materials, table S1). Triploidy of workers was confirmed by flow cytometric analyses. Even though the male who mated with the two queens could not be genotyped (see "Material and methods"), we could infer its genotype by subtracting the queen alleles from workers. The male was heterozygous at least at seven loci (supplementary materials, table S1).

We placed triploid workers from colony 24 into hibernation in the laboratory after sampling their queen for genotyping. These workers failed to produce any egg when removed from hibernation even though they were 2 to 8 months old, an age at which they should be able to do so. This differs strongly from our previous experiences of orphanage in the laboratory, where groups as small as ten orphaned workers always produced large numbers of eggs among which some developed

Table 4 Paternity of workers and gynes in the six colonies producing diploid males

\begin{tabular}{llllllll}
\hline Colony & Queen & $R_{\text {worker }}$ & Caste & $N$ & $k$ & $k e 3$ & $B$ \\
\hline $54^{\mathrm{a}}$ & No & 0.39 & $\mathrm{~W}$ & 84 & 7 & 5.55 & $\mathbf{0 . 0 3 7 ^ { * * }}$ \\
& & & $\mathrm{G}$ & $33 \mathrm{SP}$ & 7 & 6.78 & 0.003 \\
55 & Yes & 0.50 & $\mathrm{~W}$ & 26 & 5 & 3.36 & $\mathbf{0 . 0 9 2 ^ { * * }}$ \\
& & & $\mathrm{G}^{\mathrm{a}}$ & $14 \mathrm{PP}$ & - & - & - \\
100 & Yes & 0.62 & $\mathrm{~W}$ & 19 & 3 & 2.53 & 0.055 \\
& & & $\mathrm{G}^{\mathrm{a}}$ & $11 \mathrm{PP}$ & - & - & - \\
105 & Yes & 0.51 & $\mathrm{~W}$ & 40 & 4 & 3.03 & $\mathbf{0 . 0 7 7 ^ { * * }}$ \\
& & & $\mathrm{G}^{\mathrm{a}}$ & $19 \mathrm{PP}$ & - & - & - \\
120 & Yes & 0.55 & $\mathrm{~W}$ & 42 & 7 & 4.27 & $\mathbf{0 . 0 8 8 ^ { * * }}$ \\
& & & $\mathrm{G}^{\mathrm{a}}$ & $12 \mathrm{PP}+1 \mathrm{SP}$ & - & - & - \\
1090 & Yes & 0.52 & $\mathrm{~W}$ & 30 & 6 & 6.51 & -0.144 \\
& & & $\mathrm{G}$ & $6 \mathrm{PP}$ & - & - & - \\
1095 & Yes & 0.41 & $\mathrm{~W}$ & 24 & 12 & 14.58 & -0.017 \\
& & & $\mathrm{G}$ & $53 \mathrm{SP}$ & 7 & 6.38 & 0.084 \\
\hline
\end{tabular}

For each colony, the presence of a queen is noted with the mean worker relatedness $\left(R_{\text {worker }}\right)$, while sample size $(N)$, the actual number of patrilines $(k)$, the effective number of patrilines $(\mathrm{ke} 3)$ and the estimate of reproductive skew $(B)$, are given for the workers $(W)$ and gynes $(G)$. The mode of reproduction of gynes is given, with SP and PP being respectively sexually and parthenogenetically produced gynes. The value of $B$ in bold indicates that values are significant even after Bonferroni correction for the number of tests performed. All patrilines detected in gynes were found in workers

$* * p<0.001$

a data obtained from Doums et al. (2013) 
into replacement queens (Chéron et al. 2011b). The absence of eggs in colony 24 strongly suggests that triploid workers were sterile. Apart from the absence of egg-laying, we observed no obvious morphological or behavioural differences between diploid and triploid workers.

\section{Discussion}

Diploid male production has been detected in more than 80 species of social Hymenoptera (van Wilgenburg et al. 2006; Harpur et al. 2013). DMP is often used to confirm the occurrence of single-locus complementary sex determination (slCSD) and generally results from the mating of two related individuals (Cook and Crozier 1995; Heimpel and de Boer 2008). Yet, some forms of thelytokous reproduction that lead to inbreeding can also result in production of diploid males, and DMP has been suggested to be a selective force constraining the evolution of thelytoky in haplodiploid species (van Wilgenburg et al. 2006). Our results show that around $8 \%$ of adult males were diploid (12 out of 146) and resulted from thelytokous parthenogenesis in two natural populations of the ant $C$. cursor. Remarkably, $42 \%$ of these diploid males could have been produced by workers, which reflect attempts by workers to reproduce by thelytokous parthenogenesis even in the presence of the queen. On the other hand, we found no evidence of worker-produced haploid males. The diploid males of C. cursor are viable, they mate successfully and father viable but probably sterile triploid workers. Finally, we unexpectedly detected non-natal diploid males within colonies.

\section{Thelytokous parthenogenesis results in DMP in C. cursor}

The production of diploid males from thelytokous parthenogenesis found in this study contrasts with the data of Pearcy et al. (2009) who detected no such males in a different population of C. cursor. However, these authors sampled only eight colonies and the frequency of colonies producing diploid males in their study $(0 / 8)$ does not differ significantly from that of the present study (7/18; Fisher exact test $P=0.15$ ). Production of diploid males due to automictic thelytokous reproduction was reported in two other haplodiploid species: the ant P. punctata (Kellner and Heinze 2011) and the Cape honey bee (Goudie et al. 2012). Diploid males in many species might die or be selectively killed by workers at early larval stages as observed for instance in the thelytokous Cape honey bee (Goudie et al. 2012). DMP therefore may be more frequent than is generally acknowledged.

Cost of DMP is reduced in C. cursor

Production of diploid males potentially generates a costly genetic load in species using complementary sex determination
(Cook and Crozier 1995). When a female mates with a male that does not share one of her sex alleles, $100 \%$ of the diploid brood produced will develop into daughters. By contrast, when a female shares one of her sl-CSD alleles with her mate, $50 \%$ of the diploid brood will develop into daughters and $50 \%$ into diploid sons. This percentage will be reduced in multiple mating species (Crozier and Fjerdingstad 2001), like C. cursor. For the production rate of diploid males by thelytoky, the frequency of recombinant diploid males varies from 0 to 0.33 according to the position of the sex-determining locus from the centromere (Pearcy et al. 2006; Pearcy et al. 2011). In social hymenoptera, DMP not only reduces the number of reproductive females produced but it also depletes the worker force. For instance, in bumble bees' production of diploid males leads to a significant decrease in colony growth (Whitehorn et al. 2009). However, costs associated to DMP seem reduced in C. cursor. First, after the production of sexuals that occurs at the end of the hibernation period, the queen reproduces sexually only producing workers (Aron et al. 2011) and the production rate of diploid males is greatly reduced as there is no inbred mating in C. cursor (Clémencet et al. 2005). DMP therefore mainly impair the number of queen produced but not colony growth in this species. Second, when colonies reproduce by dependent colony foundation (the queen founds a new colony with the help of workers, Cronin et al. 2013), as is the case for most known thelytokous ants, the number of colonies produced is more limited by the worker force available than by the number of young queens produced. Indeed, in most colonies of $C$. cursor, the number of young queens produced exceeds the number of offspring colonies (Chéron et al. 2011a). Hence, it is unlikely that DMP would reduce the number of young queens sufficiently to affect the number of offspring colonies.

\section{Diploid males father triploid female offspring}

Implications of DMP on population dynamics depend on the survival rate and fertility of diploid males (Harpur et al. 2013). Zayed and Packer (2005) and Heimpel and de Boer (2008) showed that the negative effects of CSD on population growth are stronger when diploid males survive and mate but sire no offspring or triploid sterile offspring, than when diploid males are unviable. In $C$. cursor, diploid males are not only viable but also able to find virgin queens in natural populations. Moreover, we showed that a diploid male was able to fertilize two virgin queens that both produced viable and active triploid workers. Three triploid females (two workers and a young queen) were also found in natural populations (Doums et al. 2013), indicating that our results are not laboratory artefacts and that diploid males do father triploid offspring in the field. Fertile diploid males fathering triploid workers have been previously shown in other social hymenopteran species (wasps: P. dominulus, bees: Bombus, ants: S. invicta, T. 
erraticum, see references in "Introduction"). However, potential selective elimination of triploid brood as observed in honey bees (Santomauro et al. 2004) might greatly reduce the chance of observing triploid adult females in the field, as presumably is the case for diploid males. Moreover, polyandry could possibly be associated with sperm competition and selection against diploid male sperm to reduce their fertilization success, thereby reducing the production of triploid offspring within each colony. Finally, queen mate choice could take place and possibly reduces the mating success of diploid males. More experiments are needed to assess whether diploid male morphology and reproductive success differ from their haploid counterparts.

The triploid workers obtained in our two laboratory colonies were at a first glance not different from diploid workers as it was indeed impossible to detect visually that these workers were triploid. However, they did not lay eggs in orphaned colonies strongly suggesting that they are sterile. Triploid young queens may similarly be sterile. Given that queens are able to use either sex or thelytoky for the production of new queens (Doums et al. 2013), a queen using only thelytoky would avoid the risk of producing triploid young queens. Thus, the cost of mating with a diploid male is reduced if triploid workers are as efficient as diploid workers and if the queen produces gynes only by thelytoky. Hence, while thelytoky leads to the production of diploid males, on the one hand, it significantly reduces the primary cost of mating with diploid males, on the other. The maintenance of sex for gyne production in this species can probably be explained by the classic cost of inbreeding depression (Doums et al. 2013). Inbred gynes produced by thelytoky were indeed shown to be smaller than sexually produced gynes in one colony.

\section{Worker reproduction and cheating behaviour in queenright colonies}

As mentioned above, a proportion of diploid males are worker produced through thelytokous parthenogenesis showing that workers of C. cursor do reproduce in the presence of the queen. This contrasts with previous studies assuming that workers of this species do not lay eggs in queenright colonies (Cagniant 1979; Pearcy et al. 2006). Conversely, in the colonies studied here new gynes were mainly produced by the queens through sexual reproduction (rather than by workers through thelytokous parthenogenesis without recombination event) (Table 1, Doums et al. 2013). Based on relatedness grounds, workers would benefit more by rearing young queens produced parthenogenetically by their mother $(r=0.5)$ than young queens produced parthenogenetically by sister workers if worker-worker relatedness is lower than 0.5 (which occurs when queen mating frequency is $>2$ ). Therefore, if workers could distinguish worker produced from queen-produced gynes, there would be selective pressure for workers to remove the former at an early brood stage. A pattern of worker policing similar to the one regulating the production of males would be expected to evolve. If such worker policing occurs in C. cursor, it is surprising that worker-produced diploid males are not policed. Yet, individual selection would still favour the emergence of rare cheating behaviour, as a worker that manages to produce a young queen by thelytoky gains a huge fitness advantage if that queen succeeds in taking control of a colony. This high individual fitness benefit could explain why cheating workers are still found at low frequency (Chéron et al. 2011b) similar to that observed for haploid male production in other polyandrous species (Wenseleers and Ratnieks 2006), even though workers do not benefit collectively from reproducing. Moreover, worker thelytoky might have some advantage at the colony level since it affords high flexibility to colonies because it allows the parthenogenetic production of workers by workers and the production of a new queen should the colony lose the old one. Worker reproduction in thelytokous species therefore is not as detrimental to colony function as it is in non-thelytokous species where it only leads to the production of males. Assessing the role of worker policing is a crucial step for understanding potential conflicts and their resolution in this species.

\section{Occurrence of non-natal diploid males in C. cursor nests}

The 38 non-natal males ( $30 \%$ ) found within the nests collected are quite intriguing. We cannot completely exclude the possibility that they may have been collected inadvertently while excavating the nest. Yet, care was taken to collect external males first and it seems unlikely that collecting errors could lead to the high percentage of non-natal males observed. Whatever the origin of these males, two hypotheses may account for the occurrence of non-natal males in some nests. First, males might enter non-natal nests for mating. This is quite unexpected, as males are attacked by workers when they seek receptive gynes around the nest entrance (Lenoir et al. 1988; Cronin et al. 2011). However, some colonies may be less aggressive than others and allow males to enter. Entering a nest could be a strong advantage for the male as it could increase its chance of remating. Second, non-natal males could be produced by non-natal worker(s) who drifted into the colony and reproduced more than resident workers. In social insect species, drifting workers were generally considered as lost and harmless workers accepted by colonies. However, recent studies on honey bees and bumble bees found that in queenless colonies, a high proportion of males are produced by non-natal workers (Lopez-Vaamonde et al. 2004; Nanork et al. 2007; Takahashi et al. 2008). Drifting was even suggested to be a form of intra-specific social parasitism (Beekman et al. 2009). In C. cursor, non-natal workers occur at low frequency in queenright colonies $(0.4 \%$ in this study, 
$0.6 \%$ in Doums et al. (2013), $2.3 \%$ in Chéron et al. (2011b)). Yet, they were found to produce a high proportion of new queens through parthenogenesis in orphaned colonies (Chéron et al. 2011b), indicating that non-natal workers take part in sexual production even when they are present at a low frequency in a colony. The extent to which drifting workers contribute to the production of diploid males in colonies of C. cursor awaits further studies.

Acknowledgments We thank T. Monnin, A. Cronin, B. Gassner and two anonymous referees for their insightful comments and English improvement of the manuscript. We are grateful to the Coast Conservation Office ("Conservatoire du littoral") for allowing the collection of colonies in a protected bird nesting area. Part of this work was funded by ANR (Agence Nationale pour la Recherche) ANR-06-BLAN-0268 to C. Doums and P. Fédérici. SA thanks the Belgian FRS-FNRS for its financial support.

Conflict of interest The authors declare that they have no conflicts of interest.

Ethical standards We declare that our study complies with the current laws in France.

\section{References}

Aron S, De Menten L, Van Bockstaele D (2003) Brood sex ratio determination by flow cytometry in ants. Mol Ecol Notes 3:471-475

Aron S, Timmermans I, Pearcy M (2011) Ant queens adjust egg fertilization to benefit from both sexual and asexual reproduction. Biol Letters 7:571-573

Asplen MK, Whitfield JB, de Boer JG, Heimpel GE (2009) Ancestral state reconstruction analysis of hymenopteran sex determination mechanisms. J Evol Biol 22:1762-1769

Baudry E, Kryger P, Allsopp M, Koeniger N, Vautrin D, Mougel F, Cornuet J-M, Solignac M (2004) Whole-genome scan in thelytokous-laying workers of the Cape Honeybee (Apis mellifera capensis): central fusion, reduced recombination rates and centromere mapping using half-tetrad analysis. Genetics 167:243-252

Beekman M, Allsopp MH, Jordan LA, Lim J, Oldroyd BP (2009) A quantitative study of worker reproduction in queenright colonies of the Cape honey bee, Apis mellifera capensis. Mol Ecol 18:2722-2727

Cagniant H (1979) La parthénogenese thélytoque et arrhénotoque chez la fourmi Cataglyphis cursor Fonsc. (Hym., Form.). Cycle biologique en élevage des colonies avec reine et des colonies sans reine. Insect Soc 26:51-60

Charlesworth D, Willis JH (2009) Fundamental concepts in genetics. The genetics of inbreeding depression. Nat Rev Genet 10:783-796

Chéron B, Cronin AL, Doums C, Federici P, Haussy C, Tirard C, Monnin $\mathrm{T}$ (2011a) Unequal resource allocation among colonies produced by fission in the ant Cataglyphis cursor. Ecology 92:1448-1458

Chéron B, Monnin T, Federici P, Doums C (2011b) Variation in patriline reproductive success during queen production in orphaned colonies of the thelytokous ant Cataglyphis cursor. Mol Ecol 20:2011-2022

Clémencet J, Viginier B, Doums C (2005) Hierarchical analysis of population genetic structure in the monogynous ant Cataglyphis cursor using microsatellite and mitochondrial DNA markers. Mol Ecol 14:3735-3744

Cook J, Crozier RH (1995) Sex determination and population biology in the Hymenoptera. Trends Ecol Evol 10:281-286

Cournault L, Aron S (2008) Rapid determination of sperm number in ant queens by flow cytometry. Insect Soc 55:283-287
Cournault L, Aron S (2009) Diploid males, diploid sperm production, and triploid females in the ant Tapinoma erraticum. Naturwissenschaften 96:1393-1400

Cronin AL, Monnin T, Haussy C, Doums C (2011) Opportunities for mate choice in the fission-performing ant Cataglyphis cursor. Ecol Entomol 36:522-525

Cronin AL, Molet M, Doums C, Monnin T, Peeters C (2013) Recurrent evolution of dependent colony foundation across eusocial insects. Annu Rev Entomol 58:37-55

Crozier RH, Fjerdingstad EJ (2001) Polyandry in social Hymenoptera: disunity in diversity. Ann Zool Fenn 38:267-285

Darvill B, Lepairs O, Woodall LC, Goulson D (2012) Triploid bumblebees indicate a direct cost of inbreeding in fragmented populations. Mol Ecol 21:3988-3995

Doums C, Cronin AL, Ruel C, Fédérici P, Haussy C, Tirard C, Monnin T (2013) Facultative use of thelytokous parthenogenesis for queen production in the polyandrous ant Cataglyphis cursor. J Evol Biol 26:1431-1444

Engelstadter J (2008) Constraints on the evolution of asexual reproduction. BioEssays 30:1138-1150

Fournier D, Bataille G, Timmermans I, Aron S (2008) Genetic diversity, worker size polymorphism and division of labour in the polyandrous ant Cataglyphis cursor. Anim Behav 75:151-158

Goudie F, Allsopp MH, Beekman M, Oxley PR, Lim J, Oldroyd BP (2012) Maintenance and loss of heterozygosity in a thelytokous lineage of honey bees (Apis Mellifera Capensis). Evolution 66:1897-1906

Harpur BA, Sobhani M, Zaed A (2013) A review of the consequences of complementary sex determination and diploid male production on mating failures in the Hymenoptera. Entomol Exp Appl 146:156-164

Heimpel GE, de Boer JG (2008) Sex determination in the Hymenoptera. Annu Rev Entomol 53:209-230

Kellner K, Heinze J (2011) Mechanism of facultative parthenogenesis in the ant Platythyrea punctata. Evol Ecol 25:77-89

Krieger MJB, Ross KG, Chang CWY, Keller L (1999) Frequency and origin of triploidy in the fire ant Solenopsis invicta. Heredity $82: 142-150$

Lenoir A, Quérard L, Pondicq N, Berton F (1988) Reproduction and dispersal in the ant Cataglyphis cursor (Hymenoptera, Formicidae). Psyche 95:21-44

Liebert AE, Sumana A, Starks PT (2005) Diploid males and their triploid offspring in the paper wasp Polistes dominulus. Biol Letters 1:200-203

Lopez-Vaamonde C, Koning JW, Brown RM, Jordan WC, Bourke AFG (2004) Social parasitism by male-producing reproductive workers in a eusocial insect. Nature 430:557-560

Nanork P, Chapman NC, Wongsiri S, Lim J, Gloag RS, Oldroyd BP (2007) Social parasitism by workers in queenless and queenright Apis cerana colonies. Mol Ecol 16:1107-1114

Nielsen R, Tarpy DR, Reeve HK (2003) Estimating effective paternity number in social insects and the effective number of alleles in a population. Mol Ecol 12:3157-3164

Pamilo P, Sundstrom L, Forteluis W, Rosengren R (1994) Diploid males and colony level selection in Formica ants. Ethol Ecol Evol 6:221-235

Pearcy M, Aron S, Doums C, Keller L (2004) Conditional use of sex and parthenogenesis for worker and queen production in ants. Science 306:1780-1783

Pearcy M, Hardy O, Aron S (2006) Thelytokous parthenogenesis and its consequences on inbreeding in an ant. Heredity 96:377-382

Pearcy M, Timmermans I, Allard D, Aron S (2009) Multiple mating in the ant Cataglyphis cursor: testing the sperm limitation and the diploid male load hypotheses. Insect Soc 56:94-102

Pearcy M, Hardy O, Aron S (2011) Automictic parthenogenesis and rate of transition to homozygosity. Heredity 107:187-188

Queller DC, Goodnight KF (1989) Estimating relatedness using genetic markers. Evolution 43:258-275

Rabeling C, Kronauer DJ (2013) Thelytokous parthenogenesis in eusocial Hymenoptera. Annu Rev Entomol 58:273-292 
Rey O, Loiseau A, Facon B, Foucaud J, Orivel J, Cornuet JM, Robert S, Dobigny G, Delabie JHC, Mariano CDF, Estoup A (2011) Meiotic recombination dramatically decreased in thelytokous queens of the little fire ant and their sexually produced workers. Mol Biol Evol 28:2591-2601

Ross KG, Fletcher DJC (1986) Diploid male production - a significant colony mortality factor in the fire ant Solenopsis invicta (Hymenoptera, Formicidae). Behav Ecol Sociobiol 19:283-291

Santomauro G, Oldham NJ, Boland W, Engels W (2004) Cannibalism of diploid drone larvae in the honey bee (Apis mellifera) is released by odd pattern of cuticular substances. J Apicult Res 43:69-74

Schmeider S, Colinet D, Poirié M (2012) Tracking back the nascence of a new sex determination pathway to the ancestor of bees and ants. Nature Comm 3:895

Suomalainen E, Saura A, Lokki J (1987) Cytology and evolution in parthenogenesis. CRC, Boca Raton

Takahashi J, Ayabe T, Mitsuhata M, Shimizu I, Ono M (2008) Diploid male production in a rare and locally distributed bumblebee, Bombus florilegus (Hymenoptera, Apidae). Insect Soc $55: 43-50$ van Wilgenburg E, Driessen G, Beukeboom L (2006) Single locus complementary sex determination in Hymenoptera: an "unintelligent" design? Front Zool 3:1-15

Verma S, Ruttner F (1983) Cytological analysis of thelytokous parthenogenesis in the Cape honey bee Apis mellifera capensis. Apidologie 14:41-57

Wenseleers T, Ratnieks FLW (2006) Comparative analysis of worker reproduction and policing in eusocial Hymenoptera supports relatedness theory. Am Nat 168:E163-E179

Wenseleers T, Van Oystaeyen A (2011) Unusual modes of reproduction in social insects: shedding light on the evolutionary paradox of sex. BioEssays 33:927-937

Whitehorn PR, Tinsley MC, Brown MJF, Darvill B, Goulson D (2009) Impacts of inbreeding on bumblebee colony fitness under field conditions. BMC Evol, Biol, 9

Woyke J (1963) What happens to diploid drone larvae in a honeybee colony? J Apicult Res 2:73-75

Zayed A, Packer L (2005) Complementary sex determination substantially increases extinction proneness of haplodiploid populations. Proc Natl Acad Sci U S A 102:10742-10746 